\title{
Surveillance of listeriosis in Navarre, Spain, 1995-2005 - EPIDEMIOLOGICAL PATTERNS AND CHARACTERISATION OF CLINICAL AND FOOD ISOLATES
}

V Garrido' ${ }^{1}$ L Torroba², I García-Jalón ${ }^{1}$, A I Vitas (avitas@unav.es) ${ }^{1}$

1. Department of Microbiology and Parasitology, University of Navarre, Pamplona, Spain

2. Department of Microbiology, Virgen del Camino Hospital, Pamplona, Spain

We monitored the incidence of human listeriosis in Navarre, a region in north of Spain between 1995 and 2005, and carried out the characterisation of Listeria monocytogenes isolates obtained from clinical samples and ready-to-eat products (sliced cooked meat, smoked salmon and liver pate). The active surveillance requesting hospitals to notify all listeriosis cases $(n=40)$ yielded higher incidence rates (average annual rate 0.65/100,000 inhabitants, range $0.18-1.18 / 100,000$ inhabitants) than expected. Pregnant women were the largest group affected ( $n=13,32.5 \%$ of the cases), with a peak in incidence during the last three years of the study period. From the 40 human cases we obtained 33 Listeria isolates. Serological and molecular characterisation by PFGE identified 20 different pulsotypes, which on three occasions enabled us to link sporadic cases into clusters. Although we could not identify the incriminated food product we found two clinical pulsotypes among smoked salmon and cooked meat isolates. Surveillance of listeriosis in Spain should be improved and coordinated with other European Union Member States in order to better estimate the burden of disease and to prevent foodborne outbreaks.

\section{Introduction}

Listeria monocytogenes has been recognised as a serious foodborne pathogen, with a case-fatality rate between $20 \%$ and $50 \%$ [1-3]. However, the important impact that this disease has on public health is not always recognised, particularly since listeriosis is a relatively rare disease compared with other common foodborne infections such as salmonellosis. Listeriosis is likely to be underreported due to its status as a non-notifiable disease in many countries, including Spain, and because of the absence of adequate surveillance programs. The Community Summary Report on Trends and Sources of Zoonoses, Zoonotic Agents, Antimicrobial resistance and Foodborne outbreaks in the European Union produced jointly by the European Food Safety Authority (EFSA) [4] reported an incidence between 0 and 10 cases per million in 2006 among the 24 countries that submitted listeriosis information. It is significant that incidence rates above 5 cases per million were reported in countries where listeriosis is statutorily notifiable, such as France, Germany, Finland and Switzerland. However, even in countries with obligatory notification of listeriosis and efficient surveillance systems, such as PulseNet in the United States [5], the number of cases could be greater than reported due to the occurrence of many sporadic cases and spontaneous miscarriages which are not investigated.

As pointed out by Kiss et al. and MacKenzie et al. [6,7], integrated food chain surveillance is necessary for all national and international authorities in order to achieve adequate information regarding the true impact of listeriosis in the population. Serotyping of $L$. monocytogenes has a low discriminatory power for subtype differentiation [8], however, when combined with molecular methods based on DNA macrorestriction pattern analysis [9] it becomes a useful tool in epidemiological investigation. Among the molecular typing methods, pulsed-field gel electrophoresis (PFGE) has been one of the most frequently used in epidemiological investigation of listeriosis because of its excellent discriminatory power and reproducibility [10-15].

In Spain, the current surveillance of listeriosis is based on voluntary reporting of cases to the Microbiological Information System of the National Reference Laboratory. The present study set out to evaluate the incidence of listeriosis in Navarre, a region in northern Spain, over a period of 11 years from 1995 to 2005, by implementing active surveillance in this geographical area. The objectives of this study were:

1) to obtain epidemiological data on cases of listeriosis reported by the three main hospitals of Navarre;

2) to compare L. monocytogenes isolates recovered from food products and human cases of listeriosis in Navarre over the same period of time, by serological and PFGE characterisation.

\section{Methods}

\section{Listeriosis surveillance and epidemiological data}

In order to determine the incidence of listeriosis, we asked the three main hospitals in Navarre to report cases of listeriosis. The case definition was based on the isolation of $L$. monocytogenes from a hospitalised patient with a clinically compatible illness. A case was considered perinatal in the following cases: infected pregnant woman, miscarriage, stillbirth or newborn less than one month old. When the pathogen was isolated from both the pregnant woman and her newborn child, this was considered to represent a single case. Information regarding sex, age, clinical symptoms, immunosuppressive treatment or underlying disease, and death or recovery of the patients, was reported when available. 
In addition, patients diagnosed in 2005 were interviewed about their consumption habits with regard to high risk foodstuffs. The questionnaire (available upon request from the corresponding author) covered different aspects relating to the consumption of ready-to-eat (RTE) products (type, brand and store where purchased) during the two months preceding disease onset. Specific questions regarding high-risk RTE products sampled in the study were also included.

\section{Collection of $L$. monocytogenes strains}

A total of 87 L. monocytogenes isolates were obtained from food samples in a study which we performed in 2003-2005 [16]. Of these, 45 were isolated from a market sampling pool of 783 RTE high-risk food products that included sliced cooked meat products (pork, chicken and turkey), sliced smoked fish products (salmon and trout) and liver pate. Isolation and identification of L. monocytogenes was carried out using aseptic techniques following the NF EN ISO 11290-1 [17]. The remaining 42 food strains were obtained as a result of our earlier study on the occurrence of L. monocytogenes in the same type of RTE food products carried out in Navarre between 1995 and 2002 [18].

With respect to clinical strains, from the 40 human cases of listeriosis reported between 1995 and 2005, we were able to obtain only 33 isolates. They were isolated in the hospital microbiology laboratories and most of them originated from either blood or cerebral spinal fluid or placenta, while stool cultures for Listeria were not available. These isolates were subsequently submitted to our laboratory at the University of Navarre, where identification of strains was carried out by biochemical and serological methods.

All strains were stored at $-80^{\circ} \mathrm{C}$ in sterilised skimmed milk.

\section{Serological characterisation}

Serotyping was carried out using commercial specific antisera (Denka Seiken Co., Ltd., Tokyo, Japan) following the manufacturer's instructions. Both polyclonal anti-O antisera (O-I/II, O-V/VI, O-I, O-II, O-VI, OVII, O-VIII, Y O-IX) and anti-H (H-A, H-AB, H-C, H-D) were used in the determination of somatic and flagellar antigen, respectively. Interpretation of the results was carried out according to the serotyping scheme established by Seeliger and Höhne [19].

Molecular characterisation by pulsed-field gel electrophoresis (PFGE)

PFGE was performed according to Graves and Swaminathan [8], with minor modifications. Before performing PFGE, strains were revitalised by plating onto blood agar (Biomerieux, Marcy L'Etoile, France) and incubated at $37^{\circ} \mathrm{C}$ for $18 \mathrm{~h}$. DNA from a single Listeria colony was digested with Apal (Roche Diagnostics, Barcelona, Spain) and separated at $6 \mathrm{~V} / \mathrm{cm}$ for $19.5 \mathrm{~h}$ on a CHEF-DR II PFGE apparatus (Bio-Rad, Hercules, California, US) with switch time from 4 to 40 seconds at $14^{\circ} \mathrm{C}$. Staphylococcus aureus ATCC 29213 was used as a control for digestion. The obtained images were digitised and analysed using Gel Compar $I I ®$ software (Applied Maths, Kortrijk, Belgium). Restriction patterns were analysed using the criteria described by Tenover et al. [20]. Similarity values of the patterns were calculated using the Dice correlation coefficient with a $1.0 \%$ band position tolerance and unweighted pair group method using arithmetic average (UPGMA). Clinical and food isolates were compared, and pulsotypes were numbered consecutively.

\section{Statistical analysis}

The statistical package used was SPSS v13.0. The contingency table analysis was based on the chi square distribution (Pearson's chi square test).

\section{Results}

\section{Clinical and epidemiological data}

A total of 40 cases of listeriosis were documented in Navarre during the 11-year surveillance study period (Figure 1). Between 1995 and 2005, the mean annual incidence was $0.65 / 100,000$ inhabitants, ranging from $0.18 / 100,000$ in $1998(n=1)$ to 1.18 1100,000 in $2005(n=7)$. Table 1 shows the epidemiological data of reported cases. From the available information, 26 cases (65\%) correspond to non-perinatal infections, while perinatal infections (pregnant women and newborns) were described in 13 cases.

In total, 21 deaths were reported resulting in the average case fatality rate of $52.5 \%$. These included eight foetal deaths in

F I G U R E 1

Cases of listeriosis reported in Navarre, Spain, from 1995 to 2005 $(n=40)$

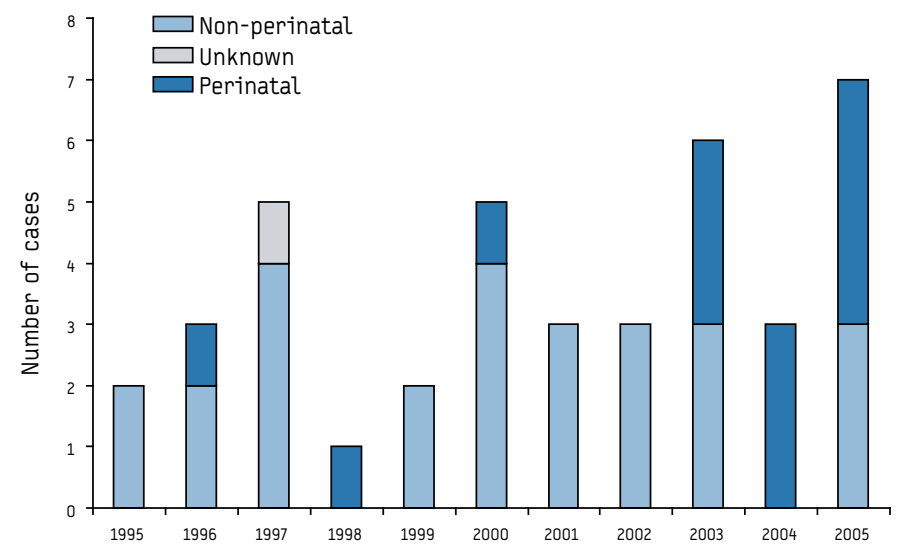

T A B L E 1

Principal characteristics of listeriosis cases reported in Navarre, Spain, from 1995 to $2005(n=40)$

\begin{tabular}{|c|c|c|c|}
\hline Epidemiological data & $\begin{array}{l}\text { Number of } \\
\text { cases ( } \% \text { of } \\
\text { the total) }\end{array}$ & $\begin{array}{l}\text { Number of } \\
\text { deaths }\end{array}$ & $\begin{array}{l}\text { Case- fatality } \\
\text { rate }(\%) \text { by } \\
\text { group }\end{array}$ \\
\hline \multicolumn{4}{|l|}{ Clinical form } \\
\hline Perinatal & $13(32.5)$ & $8^{b}$ & $61.5^{\mathrm{b}}$ \\
\hline Non-perinatal & $26(65.0)$ & 13 & 50.0 \\
\hline \multicolumn{4}{|l|}{ Risk factor (non-perinatal) } \\
\hline No detectable pathology & $5(12.5)$ & 1 & 20.0 \\
\hline Known risk ${ }^{\mathrm{C}}$ & $15(37.5)$ & 8 & 53.3 \\
\hline Other conditions ${ }^{d}$ & $6(15.0)$ & 4 & 66.7 \\
\hline \multicolumn{4}{|l|}{ Age group (in years) } \\
\hline$<1$ & 1 & 1 & 100 \\
\hline $1-19$ & $2(5.0)$ & 1 & 50.0 \\
\hline $20-39$ & $12(32.5)$ & 0 & 0 \\
\hline $40-59$ & $8(20.0)$ & 2 & 25.0 \\
\hline$>60$ & $12(30.0)$ & 8 & 66.7 \\
\hline
\end{tabular}

a Information not available in all cases

b Only foetal death (all women recovered)

${ }^{c}$ Aged $>60$ or immunocompromised patients (cancer, HIV, organ transplantation). d Chronic diseases 
perinatal cases (all women recovered) and 13 deaths among the non-perinatal cases (case-fatality rate of $50 \%$ ). Among this latter group, 15 patients (37.5\% of the total) had an underlying listeriosis risk factor defined as age $>60$ years and/or immunosuppressive conditions such as cancer, HIV or organ transplantation. Further six cases had underlying chronic conditions, such as diabetes $(n=1)$, addiction to alcohol $(n=2)$ and other $(n=3)$. The remaining five non-perinatal cases ( $12.5 \%$ of the total) were healthy people aged between 2 and 59 years.

Clinical symptoms most frequently reported were septicaemia (37.5\%) and meningitis (15.0\%) (Table 2). No cases of acute gastroenteritis caused by listeriosis were detected in the course of the study.

The most affected group at risk of listeriosis was pregnant women ( $n=13$; two of them with underlying diseases). The number

T A B L E 2

Clinical symptoms of listeriosis patients reported in Navarre, Spain, 1995-2005 $(n=40)$

\begin{tabular}{|c|c|c|}
\hline Clinical symtoms $^{\mathrm{a}}$ & Number of cases & Proportion of total (\%) \\
\hline Septicaemiab & 15 & 37.5 \\
\hline Meningitis $^{c}$ & 6 & 15.0 \\
\hline Miscarriage & 5 & 12.5 \\
\hline Stillbirth & 2 & 5.0 \\
\hline Premature & 1 & 2.5 \\
\hline Endocarditis & 2 & 5.0 \\
\hline Other ${ }^{d}$ & 5 & 12.5 \\
\hline Unkown & 5 & 12.5 \\
\hline
\end{tabular}

a Multiple responses were possible

o One case also with encephalitis

c Classified as meningitis $(n=4)$, meningoencephalitis $(n=1)$ and cerebral abscess $(n=1)$

d Hormonal disorders, arthritis, osteomyelitis, kidney failure, heart attack of perinatal cases was significantly higher in the years 2003-2005 compared with the previous period of $1995-2002$ (10 vs. 3) (Figure 2). The clinical information available showed that all of the infected mothers recovered (one of them was diagnosed with meningitis). However, $61.5 \%$ of all pregnancy-associated cases resulted in miscarriage $(n=5)$, stillbirth $(n=2)$ or infant death within 24-48 hours of birth $(n=1)$ (Table 2 ).

\section{Serotyping results}

Four serovars were determined among the 33 clinical isolates as shown in Table 3. In all of the different risk groups most of the isolates belonged to serogroup $4(78.8 \%)$. Serotype $4 \mathrm{~b}$ was the predominant $(75.8 \%, n=25)$, followed by serotype $1 / 2 a(18.2 \%$, $\mathrm{n}=6$ ). With respect to the food isolates, the predominance was for serogroup 1 (77.0\%). In contrast with the results obtained from clinical strains, serotype $1 / 2$ a was the most common $(51.7 \%$, $n=45)$, followed by serotype $4 b(23.0 \%, n=20)$, serotype $1 / 2 c$
F I G U R E 2

Incidence of listeriosis in Navarre, Spain in 1995-2005 and pregnancy-associated cases per 1,000 births in the same time period

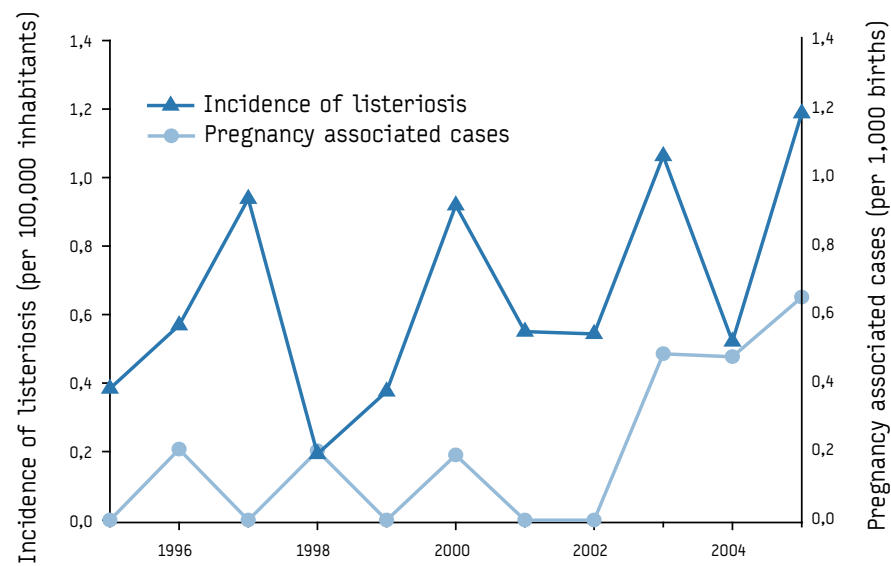

TA B L E 3

Serotype distribution of Listeria monocytogenes isolated from ready-to-eat (RTE) food and clinical cases of listeriosis in Navarre, Spain, during the period 1995-2005

\begin{tabular}{|c|c|c|c|c|c|c|c|c|}
\hline \multirow{2}{*}{ Source } & \multirow{2}{*}{$\begin{array}{l}\text { Proportion of } \\
\text { serogroup } 1(\%)\end{array}$} & \multirow{2}{*}{$\begin{array}{l}\text { Proportion of } \\
\text { serogroup } 4(\%)\end{array}$} & \multicolumn{5}{|c|}{ Number of isolates of each serotype } & \multirow{2}{*}{$\begin{array}{l}\text { Total number of } \\
\text { isolates }\end{array}$} \\
\hline & & & $1 / 2 a$ & $1 / 2 b$ & $1 / 2 \mathrm{c}$ & $4 b$ & $3 \mathrm{~b}$ & \\
\hline Clinical isolates & 21.2 & 78.8 & 6 & 1 & $-a$ & 25 & 1 & 33 \\
\hline $\begin{array}{l}\text { Non condition associated } \\
\text { with risk of listeriosis }\end{array}$ & 20.0 & 80.0 & 1 & - & - & 4 & - & 5 \\
\hline Pregnancy & 20.0 & 80.0 & 2 & - & - & 8 & & 10 \\
\hline Transplantation & 28.6 & 71.4 & 1 & 1 & - & 4 & 1 & 7 \\
\hline Cirrhosis/Alcoholism & 0 & 100 & - & - & - & 4 & - & 4 \\
\hline Cancer & 33.3 & 66.7 & 1 & - & - & 2 & - & 3 \\
\hline Others & 25.0 & 75.0 & 1 & - & - & 3 & - & 4 \\
\hline RTE foods & 77.0 & 23.0 & 45 & 3 & 19 & 20 & - & 87 \\
\hline Sliced cooked meat & 94.6 & 5.4 & 32 & 3 & 18 & 3 & - & 56 \\
\hline Sliced smoked fish & 43.3 & 56.7 & 13 & - & - & 17 & - & 30 \\
\hline Pate & $100^{b}$ & 0 & - & - & 1 & - & - & 1 \\
\hline
\end{tabular}

a No clinical isolates of this serotype detected

b Only one isolate obtained 
$(21.8 \%, n=19)$ and finally by serotype $1 / 2 b(3.5 \%, n=3)$. When food categories were examined according to serotype, we found that serotype $4 \mathrm{~b}$ was the predominant in smoked fish $(56.7 \%$, $\mathrm{n}=17$ ), while serotype $1 / 2 \mathrm{a}$ was the most frequent among sliced meat products $(57.1 \%, \mathrm{n}=32)$. The unique strain isolated in liver pate belonged to serotype $1 / 2 \mathrm{c}$.

\section{PFGE results}

PFGE revealed a total of 20 different pulsotypes among clinical isolates, distinguished by one or more band differences ranging in size from 50 to $500 \mathrm{~kb}$ (Figure 3). Pulsotypes 1, 5, 8 and 9 contained two or more strains which remained indistinguishable from each other. While strains of pulsotype $5(n=3)$ were recovered from different years, strains of pulsotype $1(n=10)$ and pulsotype 9 $(n=2)$ were related in time and geographical distribution, showing that possible outbreaks could have occurred. Among isolates with pulsotype 1 , three strains corresponded to listeriosis cases diagnosed between November and December 2003, and four were isolated from four pregnant women affected between November and December 2005. However, the oral interviews about food intake in these patients did not give us information about a possible common food source. With respect to the 87 food isolates, we found 19 different pulsotypes (data not shown), but only two of them were similar to the previous clinical pulsotypes characterised. We found a cluster of seven strains isolated from smoked salmon showing pulsotype 1. Two of these were isolated in October 2003, 1-2 months before the isolation of three clinical strains with identical

\section{F I G U R E 3}

Dendrogram for Listeria monocytogenes pulsotypes of all 33 isolates obtained from clinical cases and some isolates from food samples, Navarre, Spain, 1995-2005

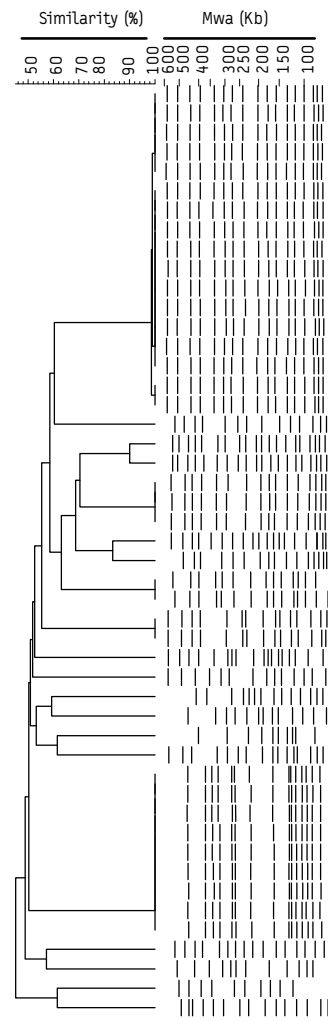

\begin{tabular}{|c|c|c|}
\hline strain & Serotype & Source \\
\hline 533 & $4 \mathrm{~b}$ & C linical case \\
\hline 612 & $4 \mathrm{~b}$ & s moked salm on \\
\hline 605 & $4 b$ & Smoked salmon \\
\hline 608 & $4 \mathrm{~b}$ & smoked salm on \\
\hline 539 & $4 b$ & $c$ linical case \\
\hline 540 & $4 b$ & $C$ linical case \\
\hline 541 & $4 b$ & C linical case \\
\hline 610 & $4 b$ & smoked salmon \\
\hline 611 & $4 \mathrm{~b}$ & Smoked salmon \\
\hline 614 & $4 b$ & smoked salmon \\
\hline 615 & $4 b$ & smoked salmon \\
\hline 552 & $4 b$ & C linical case \\
\hline 554 & $4 b$ & C linical case \\
\hline 556 & $4 b$ & C linical case \\
\hline 557 & $4 b$ & C linical case \\
\hline 558 & $4 b$ & $\mathrm{C}$ linical case \\
\hline 559 & $4 b$ & C linical case \\
\hline 72 & $4 b$ & C linical case \\
\hline 520 & $4 \mathrm{~b}$ & C linical case \\
\hline 103 & $4 \mathrm{~b}$ & C linical case \\
\hline 112 & $4 \mathrm{~b}$ & C linical case \\
\hline 522 & $4 \mathrm{~b}$ & C linical case \\
\hline 521 & $4 b$ & C linical case \\
\hline & $4 b$ & C linical case \\
\hline & & C linical case \\
\hline 528 & $1 / 2 \mathrm{a}$ & C linical case \\
\hline 529 & $\begin{array}{l}1 / 2 \mathrm{a} \\
-1\end{array}$ & C linical case \\
\hline 531 & $4 b$ & C linical case \\
\hline 532 & $4 \mathrm{~b}$ & C linical case \\
\hline 553 & $4 b$ & C linical case \\
\hline 537 & $4 b$ & C linical case \\
\hline & $3 \mathrm{~b}$ & C linical case \\
\hline 535 & & C linical case \\
\hline & $1 / 2 \mathrm{~b}$ & C linical case \\
\hline 530 & $4 \mathrm{~b}$ & C linical case \\
\hline & $1 / 2 \mathrm{a}$ & $C$ linical case \\
\hline 199 & $1 / 2 \mathrm{a}$ & Sliced meat \\
\hline 200 & $1 / 2 \mathrm{a}$ & Sliced meat \\
\hline 273 & $1 / 2 \mathrm{a}$ & sliced meat \\
\hline 53 & $1 / 2 \mathrm{a}$ & smoked salmon \\
\hline 54 & $1 / 2 \mathrm{a}$ & smoked salmon \\
\hline 55 & $1 / 2 \mathrm{a}$ & smoked salm on \\
\hline 56 & $1 / 2 \mathrm{a}$ & smoked salmon \\
\hline 57 & $1 / 2 \mathrm{a}$ & smoked salm on \\
\hline 113 & $4 b$ & $C$ linical case \\
\hline 538 & $1 / 2 \mathrm{a}$ & C linical case \\
\hline & $1 / 2 \mathrm{a}$ & C linical case \\
\hline 551 & $1 / 2 \mathrm{a}$ & C linical case \\
\hline
\end{tabular}

pulsotype. In addition, pulsotype 16 was shared by a clinical strain and seven food isolates (three isolates from sliced meat and four from smoked salmon).

\section{Discussion}

A collaborative surveillance study of Listeria infections in Europe led by the French Institut de Veille Sanitaire and Institut Pasteur [21] described an incidence of 0.15 cases per 100,000 inhabitants in the year 2000 for Spain (based on information from voluntary reporting), whilst for that same year the incidence detected for Navarre in our study was 0.91 (five cases reported in our active surveillance). Similarly, for 2004, the EFSA report [22] described an incidence of 0.20 in Spain whereas the rate obtained in our study was 0.51 (three cases). Considering that the likelihood of listeriosis in Navarre was similar to the whole of Spain (similar proportion of people at risk and food intake habits), we think that the active surveillance carried out in our study was the reason for the higher incidence obtained in Navarre compared to that reported for the whole of Spain in the mentioned publications. Similar incidence rates to those we found in Navarre were described in countries with mandatory notification of listeriosis, such as Denmark, where Gerner-Smidt et al. [23] reported incidences ranging from 0.45 to 0.75 cases per 100,000 between 1994 and 2003, and increasing to 0.8 . during 2004 [22]. It is interesting to note that the sensitivity of the Danish system for Listeria infection is thought to be almost $100 \%$ and is based on immediate notification to the National Surveillance Centre (Staten Serum Institute) of all patients from whom Listeria has been isolated. This corresponds to the methods used in our study. Likewise, active surveillance of $L$. monocytogenes infections in the Netherlands revealed an increase in incidence from 0.26 cases per 100,000 inhabitants in 2001 to 0.62 per 100,000 in 2005 [24].

It should be noted that the $52 \%$ case-fatality rate (foetal death included) obtained in our study is similar to that described in other Spanish reports [25] but higher than the average reported over recent years in the EFSA publication [4]. However, the EFSA report admits that the lower than expected reported case-fatality rate might be due to a lack of data on patient outcomes after the initial notification, which indicates the importance of clinical data recovery to assess the impact of listeriosis.

With respect to listeriosis associated with pregnancy, several authors have reported high incidences with case-fatality rates above $45 \%[6,26]$. The high numbers of listeriosis cases we detected among this group in Navarre is due, in part, to the fact that we included investigation of tissue samples obtained from hospitalised women after miscarriage. However, it should be noted that testing for L. monocytogenes was performed in a similar way during the entire study period, without a systematic analysis of all miscarriage tissues. So, the increase of the number of pregnancy-associated cases in recent years can not be considered a surveillance artefact. Taking into account that bacterial cultures are not routinely obtained from spontaneously aborted foetus or stillborn neonates in a wide range of Spanish hospitals, we believe that the true incidence of listeriosis in this risk group may still be underestimated. In order to assess the rates more accurately, we recommend the routine investigation of $L$. monocytogenes in tissue after miscarriage and stillbirth in the whole of Spain and also at European level.

To assess the real impact of listeriosis in Spain and in the whole of EU, better harmonisation of data collection systems at national 
level is required. Validated clinical and food questionnaires would be valuable in all diagnosed or suspected cases of listeriosis, providing more precise and complete information about symptoms, outcomes and food consumption habits of affected people. This way we would be able to conduct epidemiological studies (useful for outbreak investigations) and to provide dietary advice to highrisk individuals in avoiding specific foods. In our study, suspecting a possible outbreak in December 2005 after four cases had been detected in a short period of time, we decided to interview the patients using a food questionnaire but this oral survey failed to identify a possible common food source. Nevertheless, this does not exclude the possibility of a common source but rather reflects the limitations of this preliminary survey and the need for validation. Active surveillance in Italy [27] which involved distributing clinical and food questionnaires to the hospitals and the characterisation of all strains resulted in a higher number of cases of listeriosis than reported by mandatory notifications.

In addition to the accurate recovery of epidemiological information, there is a need to isolate and characterise L. monocytogenes clinical strains. Although most cases of listeriosis occur sporadically [28], serological and molecular analysis could help us to relate sporadic cases that are geographically and timerelated, allowing the detection of possible outbreaks that perhaps go unnoticed if few people are involved. Serological characterisation is useful for rapid screening of strains during suspected outbreaks. In line with the findings of several authors $[6,11,15,25,29]$ our results confirm the fact that most cases of human listeriosis are caused by serotypes $4 \mathrm{~b}$ (75.8\%). However, recent studies observed a variation of this classical distribution with an increase of serotype $1 / 2 \mathrm{a}[27,30]$.

The combination of serology and PFGE has provided us with the opportunity to link sporadic cases on three different occasions during the period 2002-2005. It should be noted that pulsotype 1 was the most frequent among the clinical strains isolated in the study (10 out of 33), and also one of the predominant profiles in the food isolates (seven isolates from smoked salmon). The profile of three patient isolates in November-December 2003 (pulsotype 1) was indistinguishable from that of two isolates obtained from smoked salmon a month before, but we had no available information about the food intake of these patients as the food questionnaire was not carried out at that time. The repeated isolation of pulsotype 1 in smoked salmon (2003-2004), and pulsotype 16 in smoked salmon and sliced cooked meat (1995-1998) suggests the persistence of specific subtypes in food processing plants. Considering that food products at risk of containing Listeria are often commercially available over a wide area, characterisation of food and clinical strains should be managed at a national level in order to trace probable sources of infection and to detect related cases occurring in other regions of Spain.

In conclusion, the present study shows that harmonised and active surveillance of listeriosis is needed in Spain in order to increase knowledge about real impact of this serious health problem. Accurate national surveillance should be based on the obligatory notification of listeriosis, the collection of epidemiological information by the application of a standardised food and clinical questionnaire and the sending of isolated strains to a reference laboratory for a serological and molecular characterisation. This active surveillance could be extended at European level, improving the available information to detect compatible cases and to trace probable sources of infection.

\section{Acknowledgements}

We wish to extend our gratitude to Dr. Inés Dorronsoro (Hospital of Navarre) and Dr. José Leiva and Dr. José Luis del Pozo (University Hospital. University of Navarre) for providing human L. monocytogenes isolates. We also wish to thank Dr. Paloma Torres and Maite Urdín (Public University of Navarre) for providing technical assistance with Gel Compar. This project was supported by a grant from Asociación de Amigos (University of Navarre).

\section{References}

1. Rocourt J, Bille J. Foodborne listeriosis. World Health Stat $Q$. 1997;50(1-2):67-73.

2. Mead PS, Slutsker L, Griffin PM, Tauxe RV. Food-related illness and death in the United States reply to Dr. Hedberg. Emerg Infect Dis. 1999;5(6): 841-2.

3. Vazquez-Boland JA, Kuhn M, Berche P, Chakraborty T, Dominguez-Bernal G, Goebel W, et al. Listeria pathogenesis and molecular virulence determinants. Clin Microbiol Rev. 2001;14(3):584-640.

4. European Food Safety Agency. The Community summary report on trends and sources of zoonoses, zoonotic agents, antimicrobial resistance and foodborne outbreaks in the European Union in 2006. EFSA: Parma, Italy; 2008. Available from: http://www.efsa.europa.eu/EFSA/efsa_locale-1178620753812_1178671312912. htm

5. Swaminathan B, Barrett TJ, Hunter SB, Tauxe RV, CDC PulseNet Task Force. PulseNet: the molecular subtyping network for foodborne bacterial disease surveillance, United States. Emerg Infect Dis. 2001;7(3):382-9.

6. Kiss R, Tirczka T, Szita G, Bernath S, Csiko G. Listeria monocytogenes food monitoring data and incidence of human listeriosis in Hungary, 2004. Int $J$ Food Microbiol. 2006;112(1):71-4.

7. MacKenzie AA, Allard DG, Perez E, Hathaway S. Food systems and the changing patterns of foodborne zoonoses. Rev Sci Tech. 2004;23(2):677-84.

8. Graves LM, Swaminathan B, Hunter SB. Subtyping Listeria monocytogenes. In: Ryser ET, Marth EH, editors. Listeria, listeriosis and food safety. New York: Marcell Dekker; 2007. p. 283-304.

9. Jacquet C, Catimel B, Brosch R, Buchrieser C, Dehaumont P, Goulet V, et al. Investigations related to the epidemic strain involved in the French listeriosis outbreak in 1992. Appl Environ Microbiol. 1995;61(6):2242-6.

10. Chou $\mathrm{CH}$, Wang C. Genetic relatedness between Listeria monocytogenes isolates from seafood and humans using PFGE and REP-PCR. Int J Food Microbiol. 2006;110(2):135-48.

11. Gilbreth SE, Call JE, Wallace FM, Scott VN, Chen Y, Luchansky JB. Relatedness of Listeria monocytogenes Isolates recovered from selected ready-to-eat foods and listeriosis patients in the United States. Appl Environ Microbiol. 2005;71(12):8115-22.

12. Okwumabua O, O'Connor M, Shull E, Strelow K, Hamacher M, Kurzynski T. et al. Characterization of Listeria monocytogenes isolates from food animal clinical cases: PFGE pattern similarity to strains from human listeriosis cases. FEMS Microbiol Lett. 2005;249(2):275-81.

13. Wagner M, Allerberger F. Characterization of Listeria monocytogenes recovered from 41 cases of sporadic listeriosis in Austria by serotyping and pulsedfield gel electrophoresis. FEMS Immunol Med Microbiol. 2003;35(3):227-34.

14. Graves LM, Swaminathan B. PulseNet standardized protocol for subtyping Listeria monocytogenes by macrorestriction and pulsed-field gel electrophoresis. Int J Food Microbiol. 2001;65(1-2):55-62.

15. Vela AI, Fernandez-Garayzabal JF, Vazquez JA, Latre MV, Blanco MM, Moreno MA, et al. Molecular typing by pulsed-field gel electrophoresis of Spanish animal and human Listeria monocytogenes isolates. Appl Environ Microbiol. 2001;67(12):5840-3.

16. Garrido V, Vitas AI, García-Jalón I Survey of Listeria monocytogenes in ready-to-eat products: prevalence by brands and retail establishments for exposure assessment of listeriosis in Northern Spain. Food Control. 2008. Forthcoming

17. Microbiology of food and animal feeding stuffs-horizontal method for the detection and enumeration of Listeria monocytogenes: Part 1. Detection method, International Standart ISO 11290-1. Geneva: International Organisation for Standardisation; 1996.

18. Vitas AI, García-Jalón I. Occurrence of Listeria monocytogenes in fresh an processed foods in Navarra (Spain). Int J Food Microbiol. 2004;90(3):349-56.

19. Seeliger H, Höhne K. Serotyping of Listeria monocytogenes and related species. In: Norris TB et al. editors. Methods in Microbiology, vol. 13. New York: Academic Press; 1979. p. 31-49. 
20. Tenover FC, Arbeit RD, Goering RV, Mickelsen PA, Murray BE, Persing DH, Swaminathan B. Interpreting chromosomal DNA restriction patterns produced by pulsed-field gel electrophoresis: criteria for bacterial strain typing. J Clin Microbiol. 1995;33(9):2233-9.

21. Institut de veille sanitaire, Institut Pasteur. Feasibility study for a collaborative surveillance of Listeria infection. October 2003. Final report. Available from: http://www.invs.sante.fr/publications/2004/listernet/

22. European Food Safety Agency. The Community summary report on trends and sources of zoonoses, zoonotic agents and antimicrobial resistance in the European Union in 2004. EFSA: Parma, Italy; 2006. Available from: http://www. efsa.europa.eu/EFSA/efsa_locale-1178620753812_1178620772157.htm

23. Gerner-Smidt P, Ethelberg S, Schiellerup P, Christensen JJ, Engberg J, Fussing $\checkmark$, et al. Invasive listeriosis in Denmark 1994-2003: a review of 299 cases with special emphasis on risk factors for mortality. Clin Microbiol Infect. 2005;11(8):618-24.

24. Doorduyn Y, de Jager CM, van der Zwaluw WK, Wannet WJ, van der Ende A Spanjaard L, van Duynhoven YT. First results of the active surveillance of Listeria monocytogenes infections in the Netherlands reveal higher than expected incidence. Euro Surveill. 2006;11(16):pii=2945. Available from: http:// www.eurosurveillance.org/ViewArticle.aspx?ArticleId $=2945$

25. Nolla-Salas J, Anto JM, Almela M, Coll P, Gasser I, Plasencia A. Incidence of listeriosis in Barcelona, Spain, in 1990. The Collaborative Study Group of Listeriosis of Barcelona. Eur J Clin Microbiol Infect Dis. 1993;12(3):157-61.

26. Siegman-Igra Y, Levin R, Weinberger M, Golan Y, Schwartz D, Samra Z, et al. Listeria monocytogenes infection in Israel and review of cases worldwide. Emerg Infect Dis. 2002;8(3): 305-10.

27. Gianfranceschi M, Gattuso A, D'Ottavio MC, Fokas S, Aureli P. Results of 12-month long enhanced surveillance of listeriosis in Italy. Euro Surveill. 2007;12(11):pij=746. Available from: http://www.eurosurveillance.org/ ViewArticle.aspx?ArticleId $=746$

28. Farber JM, Peterkin PI. Listeria monocytogenes, a food-borne pathogen. Microbiol Rev. 1991;55(3):476-511.

29. McLauchlin J. Distribution of serovars of Listeria monocytogenes isolated from different categories of patients with listeriosis. Eur J Clin Microbiol Infect Dis. 1990;9(3):210-3.

30. Lukinmaa S, Miettinen M, Nakari UM, Korkeala H, Siitonen A. Listeria monocytogenes isolates from invasive infections: variation of seroand genotypes during an 11-year period in Finland. J Clin Microbiol. 2003;41(4):1694-1700.

This article was published on 4 December 2008.

Citation style for this article: Garrido V, Torroba L, Garcia-Jalón I, Vitas AI Surveillance of listeriosis in Navarre, Spain, 1995-2005 - epidemiological pattern and characterisation of clinical and food isolates. Euro Surveill. 2008;13(49):pii=19058. Available online: http://www.eurosurveillance.org/ViewArticle.aspx?ArticleId=19058 